\title{
Summarising a summariser
}

Please send any ideas for feature articles for consideration to:

Rowena Milan,

British Dental Journal,

The Macmillan Building,

4-6 Crinan Street,

London

N1 9XW

Email:r.milan@nature.com

Earlier this year Trevor Watts finished writing the Abstracts page in the journal, having reached 1,500 abstracts since 1989.

The Editor-in-Chief caught up with him to find out how he will now fill his spare time.

Trevor Watts started writing the Abstracts for the $B D J$ in 1988, when the then Editor, Margaret Seward invited him to take on the role of making them more suitable for readers. 'I started selecting papers in the autumn of 1988 , and my first abstracts were published in 1989,' recalls Trevor, who had little idea then that the task would last the best part of 20 years and culminate in what then became his goal of having contributed a staggering 1,500 abstracts.

Until 1989 most abstracts were provided by readers who covered specific journals. Trevor reports that some were quite abstruse, being of little interest to the general practitioner or even to members of the hospital services and universities, so Margaret's aim was to establish a style and make them more suitable for the readership, starting with those taken from about 30 journals on a regular basis.

\section{Three editors}

Over the time span he has worked with three editors, the two previous being Margaret Seward and Mike Grace who then developed the Abstracts into a regular full page with four abstracts. Mike also introduced the idea of a heading sentence to capture the main thrust of a paper, which Trevor sometimes varied by drawing attention to one of the paper's implications. The popularity of it as a feature became apparent in various readership studies and market research which showed that the page was read 'always' by 20\% of readers,

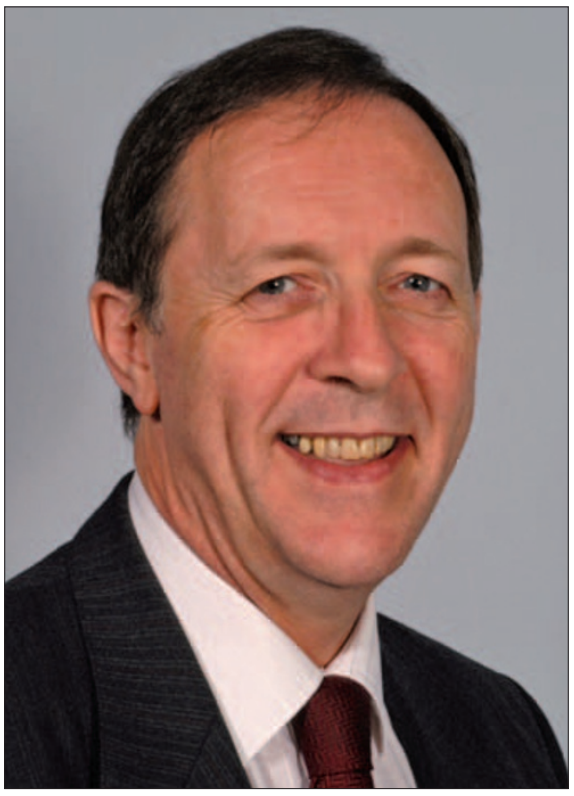

and 'frequently' by another 60\%.

The popularity was no doubt due in part to Trevor's selection of papers relevant to the readership and also the style that he developed. Although not every reader was always happy that he got it right, with the occasional author of the original paper or study complaining that the message of their work had been distorted or misrepresented in the process of summarising. Against this was the advantage that in the overwhelming majority of cases the work was being brought to the attention of a far greater audience than would have otherwise been aware of its existence.

Word processing and email made the mechanics of the job much easier, although it is now difficult to remember how we ever managed without them.
To begin with the actual abstracts were photocopied, précised on the copy and new text added to link and make sense of the changes. Proof-reader's marks guided the sub-editors to make the necessary changes and construct the new abstract ready for approval and printing. With computerisation at Guy's (where Trevor has his 'day job') in 1992, he was then able to write whole abstracts from scratch, usually in two or three short paragraphs. Further electronic developments around 1998, allowed use of pdf files of whole papers on the internet, which made the process easier still meaning that completed abstracts could be mailed to the editorial team, and they could send the pdf back for checking before publication.

\section{Selection criteria}

Crucial to the success of the regular contributions has been the selection of the papers to be included. 'My first thought was for the GDP. Would the paper be interesting, would it be relevant and would it add to or reinforce the GDP's knowledge?' explained Trevor. 'Some papers were of importance for those in more specialised areas, but they had to be made understandable to a wide range of general and specialist practitioners. Usually I chose clinical papers, especially clinical trials, and I rarely included laboratory studies. Other studies of particular interest were when cohorts of patients had been followed up for ten or even twenty years.'

Having scanned, read and abstracted 
from so many papers over the years to refine it down to the 1,500 that were published, there must have been some that stick in the mind for one reason or another. 'On reflection, one page from 2006 included two behavioural studies which made me smile' he recounted. 'In one, a characteristic described as 'cynical hostility' was related to poor oral hygiene, and in another a strategy of using a "magic trick" apparently induced young strong-willed children to sit in the dental chair more quickly!'

However, on a more serious note, the process also provided the opportunity to highlight research of particular importance such as large studies from France and Philadelphia which showed no relationship between dental treatment and endocarditis. Trevor particularly remembers case histories and especially one from the $B M J$ showing a rare complication of tetracyclines, intracranial hypertension which can lead to blindness, since shortly after summarising it he actually saw a patient who had it as a side-effect during a short course of doxycycline prescribed by a GDP, about which he then contributed a letter to the $B D J$ helpfully drawing further attention to the condition.

\section{A job well done}

I was pleased to discover that over the years Trevor hasn't found it a 'thankless' task and indeed has obviously gained a good deal of satisfaction from his regular contributions; justifiably as research over the time has variously revealed that for certain issues only the editorial and letter pages came out as being better read. He has also received kind words from colleagues in general and specialist practice, and even some of his undergraduate students at Guy's have spotted his name and writings, showing that the journal really does have an impact from colleagues' earliest days in the profession.

So, with no more abstracts to worry about how will he fill his time? It seems as if it is unlikely to a problem. Trevor will also be retiring from Guy's at the end of March 2009 but describes how his wonderful wife, three happily married daughters and seven delightful grandchildren, will benefit from seeing more of him. Using his research summarising background to the full, he told me that "the evidence suggests that to enjoy a happy old age, regular physical and mental exercise are essential. Therefore I intend to pursue a wide range of interests - walking, swimming, maybe a bit of cycling and sailing, nature-watching, cooking, reading, watching films, writing, occasionally preaching in the large and very lively Anglican church I have been a member of since 1981, and perhaps sometimes sitting in our summer-house reading a book and drinking a beer!'

If that reads like a fairly full summary of a pleasant life then we at the journal wish it to be so and of long duration. The $B D J$ and the countless readers over the last 20 years who have benefited from Trevor's skill and plain hard work are the better for his dedication and in saying a big thank you also wish him well in all of his future activities.

\section{British Dental Association Extraordinary General Meeting}

An Extraordinary General Meeting of the British Dental Association will be held at 9am on Saturday 24 January 2009 at the British Dental Association's Headquarters, 64 Wimpole Street, London W1G 8AL. Notice of the meeting and the business to be transacted was given by order of the Executive Board in the British Dental Journal edition of 20 December 2008.

\section{WELCOME}

Welcome and introduction from the Chair of the Representative Body, Stuart Johnston

\section{AMENDMENTS TO THE ARTICLES OF ASSOCIATION}

To consider and, if thought fit, approve (on recommendations of the Representative Body), changes in the provisions for the Scottish Salaried Dentists Committee and the Welsh Central Committee for Community and Public Health Dentistry, as set out in Appendix A.

\section{APPENDIX A.}

Pusuant to section 9 (1) of the Companies Act 1985 and sections 283 (1) and 283 (4) to (6) of the Companies Act 2006 and Article 79 of the Articles of Association of the British Dental Association, notice is hereby given that a vote will be held to consider (on recommendation of the Representative Body) and if thought fit, pass the following changes to the Memorandum and Articles of Association of the British Dental Association and the By - Laws thereto:

1. That in By-Law 16 (8), after the words 'Six (6) Salaried Dentists' insert the words 'there will be a minimum of two basic grade salaried dentists and two Senior or Specialist Salaried dentists'

2. That in By-Law 16 (8) delete the words 'These vacancies will be advertised...' through to '... as of right'; and following these delete the words 'There will be a minimum of two basic grade salaried dentists and two Senior Salaried Dentists'.

3. Insert as By - Law 16 (12) the heading 'Wales Committee for Community Dentists' and insert the following under that heading:

Status:

This Committee is subject to the authority of the Representative Body, from whom it seeks autonomous powers.

Remit:

The Committee exists to represent the interests of dentists working in the Community Dental Service in Wales and to make representations to their employers and to the Welsh Assembly Government on their behalf.

And further headings regarding objectives, membership, voting members, non voting members, and quorum. 